\title{
A CONTEMPORANEIDADE DA DECLARAÇÃO DE AHMEDABAD: INFLUÊNCIAS NAS POLÍTICAS PÚBLICAS PARA O FORTALECIMENTO DO DESIGN
}

\author{
Denise G. Guimarães \\ Faculdade de Arquitetura, Artes e Comunicação da UNESP \\ Campus de Bauru \\ denisefotografa@gmail.com \\ Paula da Cruz Ladim, Dra. \\ Faculdade de Arquitetura, Artes e Comunicação da UNESP \\ Campus de Bauru \\ paula@faac.unesp.br
}

Resumo: Após 37 anos de sua formulação, a Declaração de Ahmedabad continua atual. Muitas de suas diretrizes podem ser consideradas contemporâneas, principalmente aquelas que apontam nas políticas públicas o ponto de apoio fundamental para o fortalecimento do design. Este artigo abordou, através de pesquisa em documentos disponíveis tanto na internet como em arquivos de design, as principais diretrizes sugeridas na Declaração de Ahmedabad sobre Design Industrial para o Desenvolvimento (Ahmedabad Declaration on Industrial Design for Development), destacando sua contemporaneidade. É apresentado também um panorama geral das políticas públicas que promovem o design direta ou indiretamente no Brasil, a fim de suscitar a discussão sobre as contribuições possíveis à consolidação do design como ferramenta para o desenvolvimento.

Palavras-chave: desenvolvimento, design, políticas públicas, Declaração de Ahmedabad.

\begin{abstract}
After 37 years of its formulation, the Declaration of Ahmedabad is still current. Many of their guidelines may be considered contemporary, especially those that are in public policies, the point of fundamental support for the strengthening of design. This paper addressed through research documents available both on the internet and in design files, the main guidelines suggested in Ahmedabad Declaration on Industrial Design for Development (Ahmedabad Declaration on Industrial Design for Development), highlighting its contemporaneity. It also presents an overview of public policies that promote directly or indirectly design in Brazil, in order to raise the discussion of the possible contributions to the consolidation of design as a tool for development.
\end{abstract}

Keywords: development, design, public policies, Ahmedabad Declaration. 


\section{INTRODUÇÃO}

A Declaração de Ahmedabad sobre Design Industrial para o Desenvolvimento foi formulada em janeiro de 1979 , produto de uma reunião realizada na Índia pela UNIDO $^{1}$ (Organização das Nações Unidas para o Desenvolvimento), em cooperação com o ICSID ${ }^{2}$ (Conselho Internacional das Organizações de Design Industrial) e o Instituto Nacional de Design da Índia. O documento estabeleceu um plano de ações com recomendações importantes baseadas no design e direcionadas aos países em desenvolvimento.

O texto do documento citado teve início em abril de 1977, com a assinatura de um Memorando de Entendimento entre UNIDO e ICSID, e resultou em uma reunião realizada em cooperação com o Instituto Nacional de Design da Índia em 1979, com o objetivo de promover o design em países em desenvolvimento.

Desde então algumas das orientações sugeridas na Declaração já foram postas em prática. No Brasil, as políticas públicas nacionais já incluem o design em diversas ações, em geral envolvendo mais de um setor a partir de parcerias entre os ministérios federais ou com órgãos não governamentais. Mas ainda há muito a realizar no campo das políticas públicas para que o design se consolide como ferramenta para o desenvolvimento nacional. Nota-se, no Brasil, um esforço incessante para a valorização do design e, principalmente, do profissional designer, sem, no entanto, encontrar apoio suficiente por parte do poder público.

Trinta e sete anos depois de escritas, as recomendações da Declaração de Ahmedabad continuam atuais, revelando-se condizentes à realidade contemporânea das nações em desenvolvimento.

\section{A DECLARAÇÃO DE AHMEDABAD}

De acordo com documentos obtidos junto ao ICSID Archive da Universidade de Brighton, entre 14 e 24 de janeiro de 1979 mais de 130 delegados e participantes de 25 países, dentre eles o Brasil, reuniram-se em Ahmedabad e Bombaim, na Índia, para o primeiro encontro sobre Design para o Desenvolvimento. $O$ encontro foi um marco significativo no progresso da profissionalização do design, sendo considerado o primeiro encontro de design realizado com respaldo da Organização das Nações Unidas (UNIDO and ICSID, 1979).

A promessa de que o encontro seria um importante primeiro passo para a promoção do progresso industrial e o bem estar das pessoas nos países em desenvolvimento foi a tônica e grande motivadora do evento, juntamente com a preocupação de que estes países necessitavam buscar uma identidade de design que estivesse de acordo com cada cultura local.

A Declaração tem embutida a visão dos representantes e consultores da UNIDO e ICSID de que uma política governamental voltada ao design seria o primeiro passo em direção ao reconhecimento do design como ferramenta para o desenvolvimento. Para isso, sugeriu linhas de conduta para o fortalecimento do elo entre designers e indústria, com a participação ativa do governo nesse processo, incentivando a

\footnotetext{
${ }^{1}$ United Nations Industrial Development Organization

${ }^{2}$ International Council of Societies of Industrial Design
} 
promoção, disseminação, pesquisas e publicações na área do design. O documento ressaltou também a necessidade de chamar a atenção para os problemas reais enfrentados pelos países em desenvolvimento e, principalmente, a busca de soluções que não fossem meramente cópias de ações desenvolvidas por países desenvolvidos, mas sim inovações adequadas à realidade local.

Destaca-se também a orientação da utilização do design como ferramenta para a redução das desigualdades sociais, além da existência de projetos voltados às pequenas indústrias através da criação de centros de design, já que estas têm menos condições de investir em design. A proposta do documento era a de fazer com que o design ocupasse um lugar de destaque na futura estrutura sócio-econômica dos países, em longo prazo.

Nesse aspecto, Auböck (1979), destaca que a possiblidade de assistência e cooperação internacional para o desenvolvimento de políticas de design já era prevista desde 1975, data em que foi realizado outro encontro pela UNIDO, em Lima. Na Declaração de Ahmedabad, essa cooperação é prevista em um contato direto com o ICSID, buscando não apenas a transferência de tecnologia, know how e informação, mas estimular a independência da tecnologia importada, criando condições favoráveis ao próprio crescimento no processo de industrialização.

Ao final do encontro, os delegados confirmaram a Declaração de Ahmedabad sobre o Design Industrial para o Desenvolvimento como a primeira declaração internacional do gênero (ICSID Archieve, 1979). Foi a partir deste evento que alguns delegados, dentre eles o designer José Abramovitz, representando o Brasil, propuseram a criação de uma Associação Latino Americana de Desenho Industrial (ALADI), que atuou entre os anos 1980 e 1995.

A Declaração de Ahmedabad sobre o desenho industrial para o desenvolvimento é dividida em duas seções. A primeira delas consiste na apresentação das justificativas e vantagens para que países em desenvolvimento incluam o design industrial em seus processos de planejamento. Um plano de ação é apresentado, sugerindo medidas a serem tomadas pelo poder público em favor do design. Dentre as principais medidas estão: o estímulo e apoio a associações de design e instituições para a promoção do design, através das quais o design deve ser incorporado aos planos de desenvolvimento nacional, consolidando uma consciência nacional de design. Nesse sentido, a educação deve receber apoio assim como prêmios, exposições e publicações na área devem ser incentivadas.

O documento sugere que sejam estabelecidos sistemas de cooperação ativa entre instituições de design de países desenvolvidos e menos desenvolvidos, com apoio de organizações internacionais como ICSID, Unesco, WHO, além de bancos de desenvolvimento mundiais.

Na segunda seção, são apresentadas recomendações de políticas de design, ações governamentais, indústria, educação e cooperação interna, detalhadamente. Dentre as recomendações para políticas públicas, destacam-se as ações para a colocação correta do designer industrial nas indústrias a partir de uma política nacional e a promoção do design entre as empresas de pequeno porte, num processo gradual e de melhoria contínua. 
A valorização dos profissionais é um ponto importante a ser destacado; a recomendação é que a remuneração do trabalho do designer varie de acordo com valores vigentes na indústria, de forma a atrair e evitar a evasão de talentos.

As ações governamentais são apontadas como importantes para prover uma base para o entendimento da profissão de designer, sem a qual a aceitação do profissional designer não se dá rapidamente. É de responsabilidade do governo também o financiamento adequado para o pessoal, equipamentos, materiais e formação de profissionais.

Para as indústrias, o documento sugere o uso de tecnologia adequada em uma infraestrutura simples, de baixo custo, de fácil manutenção, mão de obra intensiva e compatível com os padrões socioculturais, dentre outros.

$\mathrm{Na}$ formação do profissional de design é destacada a importância da abordagem multidisciplinar e do trabalho em estreita colaboração com profissionais de diferentes áreas, assim o conceito de trabalho em equipe deve ser integrado na estratégia de design. Bibliotecas referenciais, coleções permanentes de objetos e o apoio à pesquisa devem ser apoiados pelo poder público.

\subsection{0 design para o desenvolvimento e as políticas públicas no Brasil}

De acordo com Margolin (2009), nos anos posteriores à Declaração, UNIDO e ICSID seguiram uma concepção mais restrita, diferentemente das recomendações apresentadas na Declaração de Ahmedabad. O autor afirma que a estrutura tripartite que classificava os países em Primeiro, Segundo e Terceiro Mundo teria prejudicado a transferência de ajuda e apoio técnico aos países mais pobres, atrasando, assim, seu desenvolvimento. A Declaração, embora pertinente e inovadora para a época, permaneceu como um protocolo de intenções, mas pouco colocada em prática (BALARAM, 2009).

Maldonado (1991) afirma que as metas pré-fixadas de alavancar o processo de desenvolvimento dos países "periféricos" não foram alcançadas, pois, mesmo nos casos de transferência de tecnologia, esta ocorreu ao acaso e em algumas situações gerou resultados negativos, promovendo outras formas de subdesenvolvimento e tornando a dependência dos países subdesenvolvidos ainda maior.

Na prática, a transferência tecnológica deu-se através da transferência de produtos. Estes, embora fabricados total ou parcialmente nos países em desenvolvimento, possuíam projetos de design desenvolvidos nos países de origem, limitando a intervenção e desenvolvimento do design local. Dessa forma, as recomendações da Declaração de Ahmedabad foram desconsideradas (BONSIEPE, 2011).

No Brasil, as discussões sobre a importância do design para o desenvolvimento começaram a partir da década de 1950, com a política industrializante de Juscelino Kubitschek (NIEMEYER, 2007). Mas isso não significou efetivamente que após a Declaração de Ahmedabad o design brasileiro tenha recebido a devida atenção das políticas públicas nacionais ou o apoio de órgãos internacionais.

A política orientada à substituição das importações, que vigorou nas décadas de 1960/70 no Brasil, provocou uma retração no desenvolvimento tecnológico. A 
economia voltou-se para o mercado interno e, distante da concorrência dos produtos industrializados e com padrão de qualidade internacional, não investiu o suficiente para que o design se fortalecesse.

Nesse sentido, foi de importância fundamental para a valorização e crescimento do design a mudança no paradigma do desenvolvimento na década de 1980, o qual foi ampliado para desenvolvimento humano, em que os fatores econômicos deixaram de ser parâmetro único para medir o desenvolvimento de uma nação.

Uma mudança no paradigma do desenvolvimento ocorreu começo dos anos 80 em que uma série de comissões internacionais tanto de dentro como fora das Nações Unidas expandiu a definição do desenvolvimento para incluir a habilidade de criar o bem estar humano e não apenas uma infra- estrutura econômica. (Margolin, 2009, p.2).

As questões de investimento e políticas públicas para o design ganharam força apenas a partir dos anos 1990, aliadas aos incentivos econômicos para o crescimento do país, que hoje já alcança o reconhecimento internacional entre as principais nações em desenvolvimento no mundo.

Diversas ações já fizeram ou fazem parte das políticas públicas de promoção ao design brasileiro. Dentre elas, destaca-se a criação do Programa Brasileiro de Design (PBD), em 1995, e que atua até hoje. Sua criação marcou o início de uma etapa em que o design passou a fazer parte das políticas de incentivo ao desenvolvimento. Dentre as atividades produzidas pelo PBD, estão ações e projetos diretamente ligados ao design, como a realização da Bienal Brasileira de Design, para dar visibilidade ao design brasileiro; a criação do Design Excellence Brazil, a fim de apoiar a participação de empresas e estudantes brasileiros na premiação internacional IF Awards ${ }^{3}$.

O PBD está ligado ao Ministério de Desenvolvimento, Indústria e Comércio Exterior (MDIC), assim como entidades que possuem ações voltadas à promoção e desenvolvimento do design aliados ao desenvolvimento econômico e industrial, como a Agência Brasileira de Desenvolvimento Industrial (ABDI), o Banco Nacional de Desenvolvimento Econômico e Social (BNDES) e a Agência Brasileira de Promoção de Exportações e Investimentos (Apex-Brasil).

O design também é favorecido em ações do Ministério da Ciência, Tecnologia e Inovação (MCTI), através do fomento à pesquisa científica e tecnológica financiada pelo Conselho Nacional de Desenvolvimento Científico e Tecnológico (CNPq), e indiretamente em financiamentos de ciências e tecnologia pela agência Financiadora de Estudos e Projetos (Finep).

Através do Ministério da Educação (MEC), o design tem o incentivo e a regulação para a formação de profissionais capacitados, através do ensino superior em instituições públicas ou privadas, ensino técnico e também o investimento na consolidação dos programas de pós-graduação, através da Coordenação de Aperfeiçoamento de Pessoal de Nível Superior (Capes).

\footnotetext{
${ }^{3}$ Ministério do Desenvolvimento, Indústria e Comércio Exterior. Disponível em: <http://www.desenvolvimento.gov.br>. Acesso em: 10 abr. 2015.
} 
O design é também objeto de apoio em instituições privadas, de capital misto ou entidades sem fins lucrativos, como a Confederação Nacional da Indústria (CNI), Serviço Brasileiro de Apoio às Micro e Pequenas Empresas (Sebrae), Serviço Nacional de Aprendizagem Comercial (Senac), além de centros de design e associações.

Por fim, a partir de 2010, o Ministério da Cultura (Minc) incluiu o eixo Economia Criativa para a construção de estratégias setoriais, promovendo ações voltadas a popularização do design, dentro de uma política de valorização da cultura local e regional. Com a criação da Secretaria da Economia Criativa, o design passou a ser contemplado em ações paralelas desenvolvidas pelo Minc em parceria com outros ministérios ${ }^{4}$. Em 2014 foi realizada uma consulta pública, que estabeleceu o Plano Setorial Design, com orientações para ações de políticas públicas voltadas ao design até o ano 2026, junto ao Minc.

O Plano Setorial foi desenvolvido com base em quatro eixos que envolvem Criação, produção e desenvolvimento; Difusão e acesso à cultura; Memória e diversidade cultural e por fim, Estrutura e gestão. Os pontos detalhados em cada um dos eixos descritos coincidem com as principais diretrizes apontadas na Declaração de Ahmedabad.

\section{CONCLUSÃO}

Com 36 anos de existência, a Declaração de Ahmedabad traz recomendações que poderiam ter sido escritas nos dias atuais, como o reconhecimento e utilização do design como ferramenta para o desenvolvimento e o investimento em um design alinhado com as necessidades locais.

No Brasil, uma série de medidas já inclui o design nas políticas públicas vigentes, tanto em investimentos na formação acadêmica e técnica de profissionais, como para as empresas de um modo geral, com incentivos para pesquisa e desenvolvimento.

Uma das recomendações da Declaração de Ahmedabad que ainda merece atenção é a valorização do profissional designer. Basta considerar que a regulamentação da profissão ainda não se concretizou, em uma luta que começou em 1980 e passou por sete projetos de lei. O último deles, vetado pela presidente Dilma Roussef em 2015, após já ter sido aprovado pelo Senado.

Assim como afirmado na Declaração, a valorização do profissional é necessária para o avanço e a aceitação da profissão. O Brasil já melhorou muito, mas muito ainda pode ser feito em favor do design, e, com o design em favor do Brasil. Projetos de parceria que relacionem os setores público e privado podem favorecer a colocação de profissionais no mercado de trabalho, ao mesmo tempo em que permitem aos profissionais o acesso às empresas e às empresas a retenção de talentos.

Políticas públicas assertivas que priorizem e valorizem o design, programas acessíveis aos empresários brasileiros e novas estratégias de popularização do design tornariam o design mais acessível.

\footnotetext{
${ }^{4}$ Ministério da Cultura. Plano da Secretaria da Economia Criativa: políticas, diretrizes e ações 2011-2014. 1a edição. Disponível em: <http://www.cultura.gov.br>. Acesso em: 10 abr. 2015.
} 
Nesse sentido, o Plano Setorial Design Brasil-2026 aborda pontos importantes que dialogam com as diretrizes apontadas pela Declaração de Ahmedabad, comprovando sua contemporaneidade. Postos em prática, poderão fortalecer o design e valorizar a profissão de designer.

\section{REFERÊNCIAS}

BALARAM, S. Design in India: The importance of the Ahmedabad Declaration. Design Issues Volume 25, Issue 4, p54-79. Number 4 Autumn 2009. In:

<buscaintegrada.usp.br>, 11/09/2014.

BONSIEPE, Gui. Design, cultura e sociedade. São Paulo: Blücher, 2011.

ICSID Archive, University of Brighton Design Archives. Ahmedabad Declaration on Industrial Design for Development.

ICSID Archive, University of Brighton Design Archives. Background paper on 'The Role of Industrial Design in the Industrialisation of Developing Countries' by Carl Aubock.

ICSID Archieve, University of Brighton Design Archives. UNIDO-ICSID ÍNDIA'79:

Ahmedabad Declaration reflects a historic meeting. 1979.

Design as a Strategy for a Developing Economy. IDC Industrial Design Centre IIT Bombay. In: <http://www.idc.iitb.ac.in/resources/reports/desing-as-a-strategydeveloping-economy.pdf>, 06 /09/ 2014.

MARGOLIN, Victor. Design para o desenvolvimento: para uma história. Revista Arcos Design 4, Janeiro de 2009. In: < http://www.esdi.uerj.br/arcos/arcos-04-1/04-1.arcosdesign-04-1-completo.pdf>, 06/09/2014.

MALDONADO, Tomás. Design industrial. Lisboa: Edições 70 LDA, 2006.

MINISTÉRIO DA CULTURA. Plano da Secretaria da Economia Criativa: políticas, diretrizes e ações 2011-2014. 1a edição. In: Home: Minc: <http://www.cultura.gov.br>. Acesso em: 10 dez. 2014.

MINISTÉRIO DO DESENVOLVIMENTO, INDÚSTRIA E COMÉRCIO EXTERIOR. In: Home: MDIC <http://www.desenvolvimento.gov.br>. Acesso em: $10 \mathrm{dez} .2014$.

NIEMEYER, Lucy. Design no Brasil: Origens e instalação. 4 ed. Rio de Janeiro: 2AB, 2007.

PATROCÍNIO, Gabriel; BOLTON, Simon. European influences on brazilian public design policies. Anais... VI Congresso Internacional de Pesquisa em Design (CIPED). Lisboa: CIPED, ANPEDesign, CIAUD, 2011. 